\title{
أزمة الرهن العقاري وانعكاساتها في اقتصاديات الدول العربية وطرق علاجها
}

\section{م.م ليلى عبدالكريم عحمد الهاثيّي جامعة الموصل / كلية الإدارة والاقيصاد}

\author{
د. سراء سالم داؤد الجزجوسي \\ جامعة الموصل / كلية الإدارة والاقتصاد
}

| (اللخص

إن أسس المندسة المالية المنبثقة من الفكر الاقتصادي الرأسمالي الحر لها الأثر الكبير في حدوث الأزمات المالية، وأثر هذه الهندسة ظهر كفقاعة يظهر هنا وهناك ولكن في النهاية تتدحرج مثل كرة الثلج يزيد حجمها وتمتد مسافات طويلة ويصبح أثرها أكبر وأكثر وضوحاً. ومن المثفق عليه إن الأزمة المالية العالمية في سنة ^ م. . ب بدأت في قطاع الرهن العقاري في الولايات المتحدة الأمريكية فانخفت قيمة العقارات، مما أدى إلى ضعف قدرة المصارف على تسديد التزاماتها تجاه المؤسسات المالية الأخرى وضعف قدرة الأفراد على التسديد ديونهم تجاه المصارف. ولكن الحقيقة أكبر من هذا ويتم توضيحها في مبحثين يتناول المبحث الأول أسباب فقاعة الرهن العقاري وانفجارها في سنة ^ ـ . r ومعرف جذورها وأسبابها وكيفية تحول أزمة الرهن العقاري إلى أزمة سيولة وأزمة عدم قدرة على السداد للديون وفوائدها، أما المبحث الثاني تناول تأثير هذه الأزمة في اقتصاديات بعض الدول العربية منها النفطية وغير النفطية ومعرفة تأثيرها على بعض المتغيرات الاقتصادية والأسواق المالية لهذه الدول، ومن خلال مجمل ما عرضه البحث تم التوصل إلى مجموعة من الاستنتاجات والمقتزحات أهمها إن السبب الرئيس لانفجار الفقاعة المالية هو الاستخدام السئ للمشتقات المالية والتوسع والافر اط في منح القروض العقارية للأفف اد و الشر كات لقاء تسهيلات مصرفية وعدم تنويع في الضمانات والتزكيز على الضمانات العقارية من قبل المصارف الأمريكية، وانعكس ذلك بتوصية مفادها تبني مؤشرات الإنذار المبكر لمراقبة البيئة الداخلية والخارجية للتمكن من اكتشاف الأزمة في بداية تكوينها.

\section{Abstract:}

The foundations of financial engineering emanating from the capitalist economic thought free a significant impact in a financial crisis, the impact of this geometry appeared as a bubble shows here and there but in the end, rolling like a snowball larger than stretching long distances and become impact bigger and more and agreed that the financial crisis global in 2008 began in the mortgage sector in the United States of America real estate values dropped, which led to weak bank's ability to repay its obligations to other financial institutions and the weakness of the ability of individuals to repay debts to the banks. But the truth is greater than this and are described in two sections deals with the first part, the causes of the mortgage bubble bursting in 2008 and defined the root causes and how to shift the mortgage crisis into a liquidity crisis and a crisis of inability to repay debt and benefits.

$$
\text { قدم هذا البحث في المؤتمر العلمي الدولي الرابع لجامعة التنمية البشرية/نيسان V V . P }
$$


The second topic dealt with the impact of this crisis in the economies of some Arab countries, including oil and non-oil and their impact on certain economic variables and financial markets of these countries, and through the whole what has been presented research was to reach a set of conclusions and proposals notably that the main reason for the explosion of the financial bubble is the wrong use financial derivatives, expansion and over-the granting of mortgage loans to individuals and companies to meet with banking facilities and failure to diversify in guarantees and a focus on real estate collateral by US banks, and is reflected in the research to reach a recommendation that the adoption of the early warning indicators to monitor the internal and external environment to be able to detect the crisis in the beginning of the composition.

\section{مقدمة}

الأزمات المالية الحدث المفاجئ المقتزن بالتهديد والخطر غير المتوقع، إذ يقضي على أهداف المنظمات والشركات والاقتصاد في

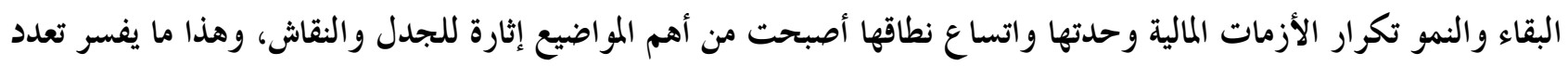
واختلاف التوجهات والمدارس الاقتصادية التي فسرت الأزمات المالية التي تعمل على الانتقال من نقطة بداية إلى أخرى والانتقال من فكر اقتصادي إلى فكر اقنصادي جديد. والأزمات المالية ليست وليدة نظام مالي حديث أو قديم ولكنها مرهونة بظاهرة الانتشار السريع، وهذه الأزمات الحمديثة تتميز بظاهرة الارتباط والانتقال و العدوى السريعة بسبب العولمة والتطورات السريعة في تكنولوجيا الأعمال والمنظمات التي تسير على النظم المفتوحة، فلابد أن تتأثر وتثٔثر في البيئات الخيطة لها، وهذه الأزمات أخذت لتشمل دول نامية ومتقدمة وتئثر في مستوى النشاط الاقتصادي والنمو الاقتصادي وتوازن الميزانية واستقرار الأسعار وحجم الائتمان وتثٔثر بشكل مباشر في الأسواق المالية (البورصات)، إلى جانب آثارها الاجتماعية من حيث البطالة والفقر. ويتكون البحث من جانبين، الجانب الأول نظري، يتم فيه توضيح وتفسير وتحليل لأزمة الرهن العقاري من حيث أسبابها وجذورها ومظاهرها على الاقتصاد الأمريكي. والجانب الثاني العملي يبين فيه أثر أزمة الرهن العقاري على بعض الدول العربية منها النفطية وغير النفطية وبتأثيرها المباشر وغير المباشر وتحليل بعض المؤشرات المالية والاقتصادية لهذه الدول من حيث التذبذب في أسعار النفط، التغيرات في الصادرات و الواردات، والناتج الخلي الإجمالي، والتغيرات في اسعار الاسهم في البورصة العربية. مشكلة البحث تظهر عدة تسأولات للبحث ومنها: ا ـ ماهي جذور أزمة الرهن العقاري وبداياتها. r. ماهي الأسباب المباشرة التي أدت إلى حدوث أزمة الرهن العقاري. آ. ماهي آثارها على اقتصاديات بعض الدول العربية ومدى الخطورة التي تعرض لها اقتصاديات الدول العربية نتيجة الانفتاح الاقتصادي والمالي والتزابط المالي في ظل آلية العولمة مع الاقتصاد الأمريكي. 
الأزمات المالية ماهي إلا نتاج لمشكلات متنوعة ومتزاكمة، وإن حدوث أزمة الرمات الرهن العقاري سبت المبالغة في قياس العقارات

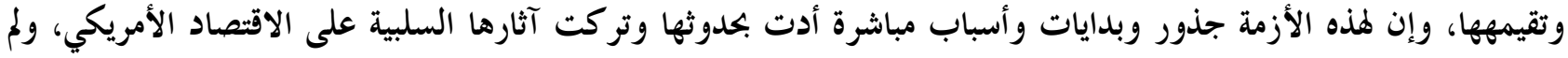
يكتف بهذا بل انتقل بآثارها وسلبياتها على اقتصاديات العالم ومنها الدول العربية بسبب الارتباط المباشر وغير المباشر بين

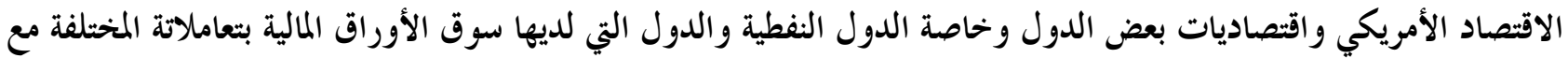

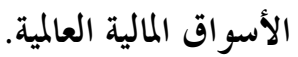

مدف البحث

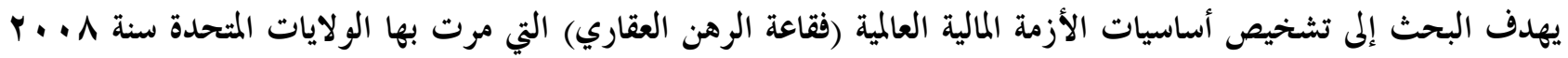

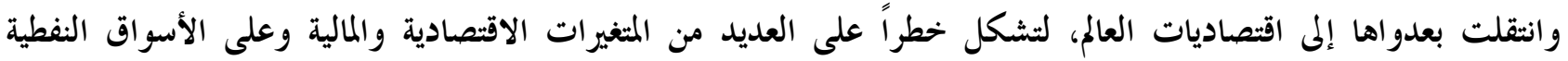
وأسواق الأوراق المالية ومعرفة مدى هذا التأثير المباشر وغير المباشر على بعض الدول العربية النفطية وغير النفطية.

\section{المجحث الأول}

\section{مفهوم أزمة الرمن العقاري وجذورها وأسبابها}

أولاً. مفهوم أزمة الرهن العقاري ظهرت عدة مفاهيم للأزمة المالية العالمية التي اطلق عليها أزمة الرهن العقاري من قبل العديد من الباحثين والماليين والاقتصاديين

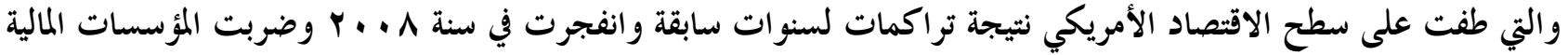

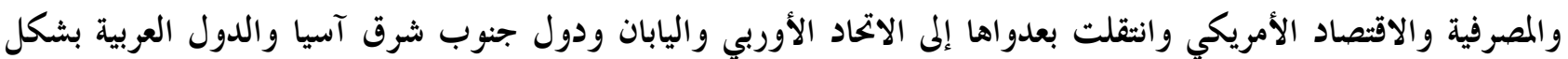
مباشر وغير مباشر.

\section{وبالإمكان أن نعطي مفاميم هلذه الأزمة}

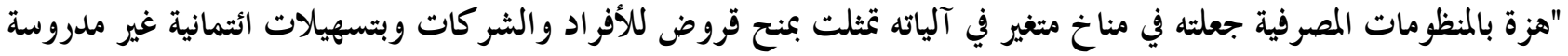

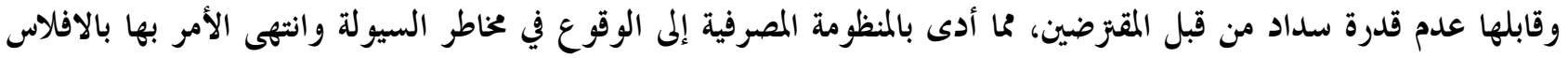
وتحويل الرهونات إلى أوراق مالية من قبل الشركات والكيانات الاستثمارية في سوق الأوراق المالية".

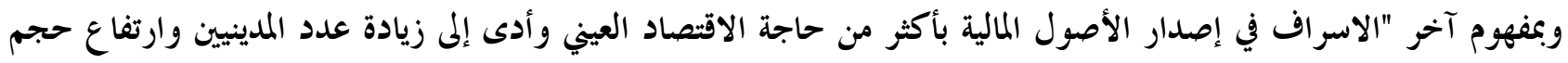
المخاطر وعجزهم عن التسديد لقروضهم العقارية". وإعطاء مفهوم آخر بأنها "عجز كبير أصاب القروض الائتمانية الرهينة للأسر الأمريكية، أدى إلى صعوبات مالية قوية وحادة في

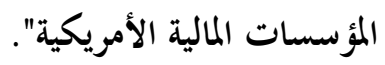
وهناك مفهوم آخر يتمثل "بانتفاخ الفقاعة العقارية وانفجارها نتيجة حالة توقف الأفراد عن سداد ديونهم للمؤسسات المصرفية

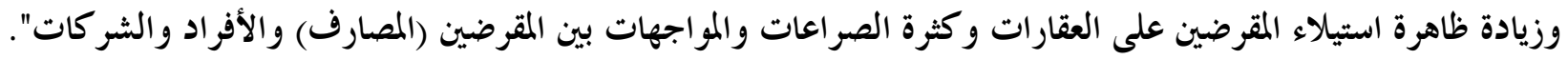




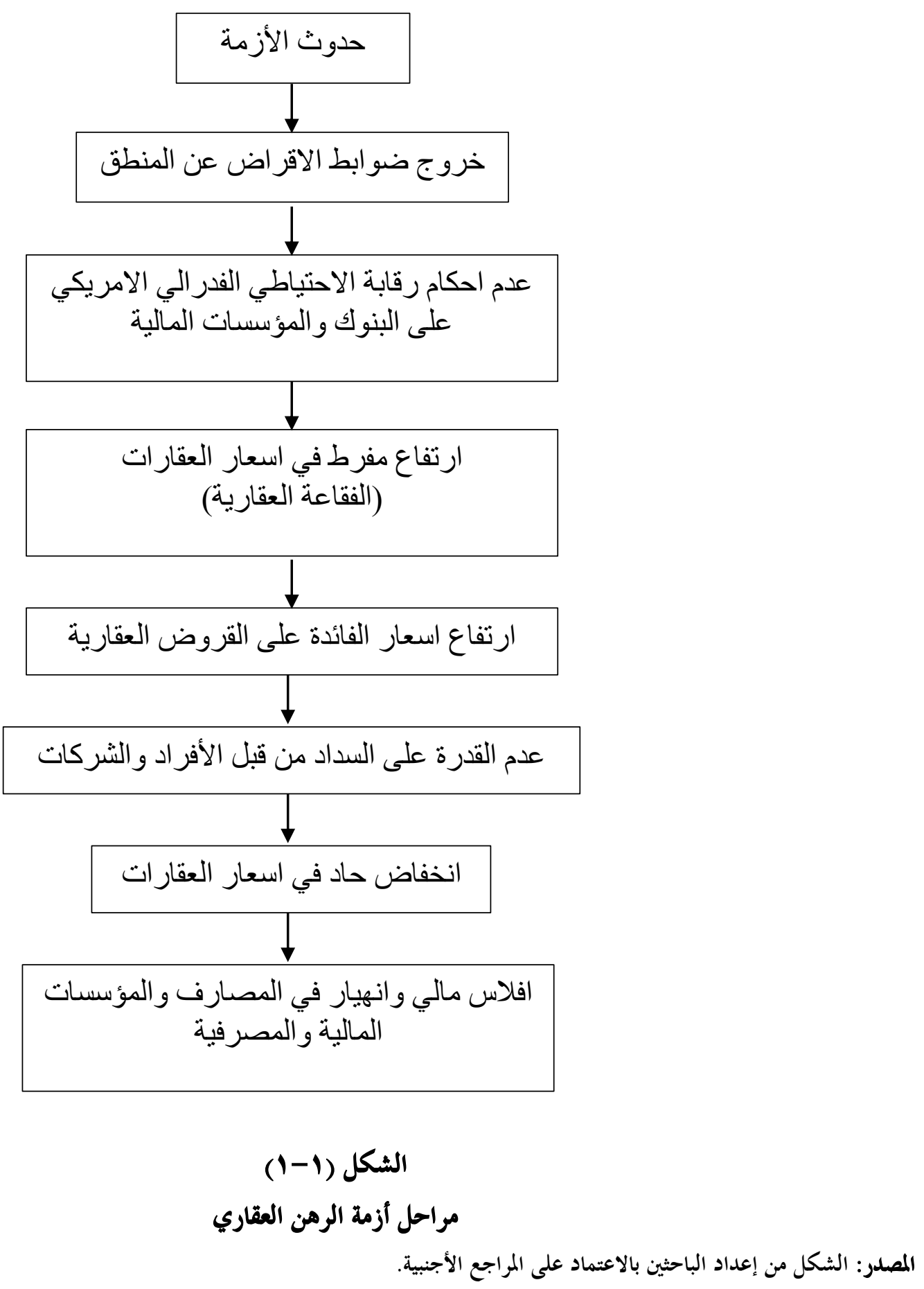


ثالياً. جذور الأزمة

كل فرد في أي دولة كانت سواء في الولايات المتحدة وفي دول متقدمة ودول نامية يرغب بالحصول على عقار ويمتلكه، وخاصة إن السياسة المعتمدة في الولايات المتحدة بشراء العقارات بالتقسيط وضمن إجراءات معينة من خلال الحصول على قروض مقابل فوائد وبتسهيلات ائتمانية سهلة على الأفراد، ويتم شراء العقار بأموال القرض ولكن يوجد شرط أساسي أن تكون أسعار الفائدة متغيرة ومرتبطة بسعر البنك المركزي الذي يعلن عنه، وعند تأخر السداد من قبل المقزض تنضاعف سعر الفائدة عليه

(Mazen,2008,533-534)

كما ان المدفوعات الشهرية خلال السنوات الثلاثة الاولى فقط لسداد الفوائد ولا تذهب المى ملكية جزء من العقار إلا بعد مرور ثلاث سنوات ولكن هناك مسألة مهمة في حالة ارتفاع اسعار العقارات يحصل خيارات أمام مالكها، إما ان يبيع عقاراته لتحقيق أرباح عالية أو يحاول الحصول على قرض مقابل رهن جزء من العقار إذا ارتفعت قيمتله. والمؤسسات المالية في هذه الحالة تلجأ المى بيع القرض كسندات للمستثمرين فيزيد من ارباحهم وممكن ان يرهن المستثمرين سنداتهم وللأطمئنان يقومون بالتأمين عليها لدى شر كات التأمين ومن خلال رهن سنداتهم يحصلون على قرض جديد وسيولة

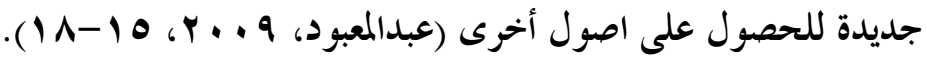
ولكن بالنتيجة الختملة لسلوك الأفراد هي افلاسهم واضطرارهم لبيع عقاراتهم دعما للسندات فيزداد عرض العقارات مما يؤدي الى الخفاض اسواقها والدخول اللى مرحلة الكساد وعلى مستوى الاقتصاد الكلي حصل افلاس البنوك الاستثمارية وصناديق الاستثمار وشر كات التأمين، مما سبب في انهيار سوق العقارات السكنية في الولايات المتحدة الامريكية نتيجة الافراط في تقديم القروض للمقتزضين (أفراد وشركات) ومتاحة للجميع ولكافة الفئات الدخلية ومنها المتوسطة والمنخفضة الدخل وبضمانات سهلة، مما ادى المى ارتفاع اسعار العقارات بشكل اكثر من الخسوب والمتوقع فزاد منح القروض من قبل البنوك وزاد شراء المزيد من الاوراق المالية التي بحوزة تلك البنوك نتيجة بيع المساكن هذه من جهة، ومن جهة اخرى توريق الرهونات في سوق الاوراق المالية التي لها تصنيف من خلال تقسيمها المى مشتقات معقدة من الانتباه المى حجم المخاطر التي تتحملها هذه المشتقات المالية وبعيدة عن الجهات الرقابية والتنظيمية (Hershey \&Friedman,2009,10). وهذه الفقاعة العقارية انفجرت وتراجعت اسعار العقارات بشكل كبير وزاد الثأخير عن السداد من قبل الأفراد والشركات وتدهور التصنيف الائتماني للاوراق المالية وبدأت الاضطرابات تزداد في سوق النقد وبدأ الاخفاق يزداد في اكبر البنوك الاستثمارية في الولايات المتحدة الامريكية في الوفاء بالتزاماتها واعلان افلاسها في سنة م ـ. . ب وظهرت حالة عدم الثقة وشحة السيولة ومحاولة استزجاع الاموال من خلال بيع القروض في سوق الاوراق المالية في اكبر المصارف الاستثمارية في الولايات

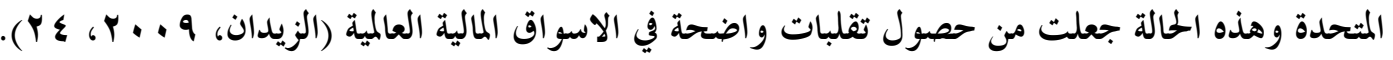




\section{رابعاً. مظاهر أزمة الرهن العقاري}

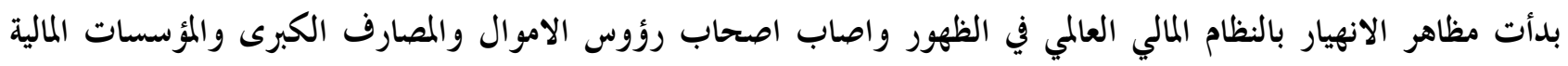

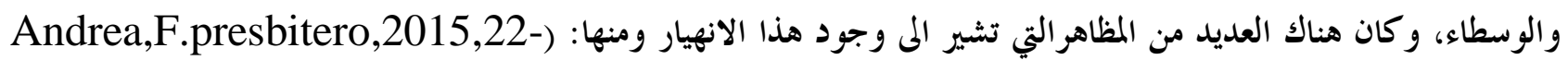

1. انخفاض مستوى استخدام الموارد الاقتصادية نتيجة انخفاض مستوى السيولة وتجميد الحصول على القروض من المؤسسات

المالية.

r. . انخفاض مستوى المبيعات وخاصة في سوق العقارات وغيرها من السلع شبه الضرورية وشبه الكمالية بسبب نقص السيولة.

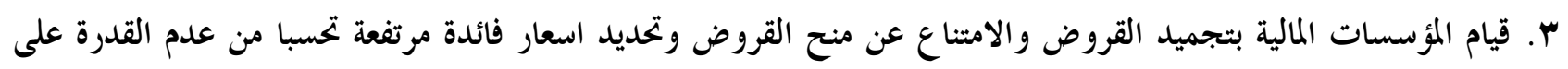
السداد من قبل الأفراد والشر كات.

ع. سحب مفاجئ للودائع من البنوك خوفا من نقص السيولة وعدم قدرة البنوك الوفاء بالتزاماتها المالية. هـ انخفاض مستوى التداولات في الاسو اق المالية واسو اق النقد . ج. انخفاض في مستوى الصادرات والواردات بين معظم دول العالم التي حصلت فيها الازمة المالية والدول التي انتلت اليها الازمة.

V. انخفاض معدلات الاستهلاك والانفاق والادخار والاستثمار العام والحاص. ^. ارتفاع معدلات البطالة والكساد واصبح حالات التعثر المالي والتصفية والافلاس لكبار المؤسسات المالية.

خحامساً. أسباب الأزمة المالية العالمية (أزمة الرمن العقاري)

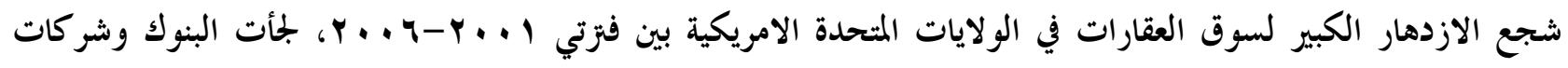

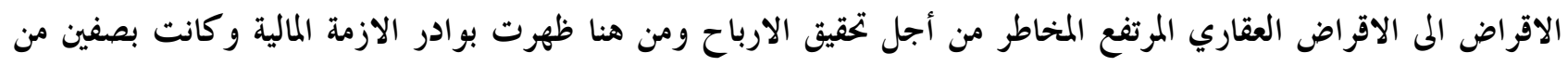

الدومينو (Orlowski LucjamT.sacred,2008, 11). الصف الأول: صف الدومينو سقط عندما أصبح ليس بمقدور الأفراد تسديد القروض وفو ائدها.

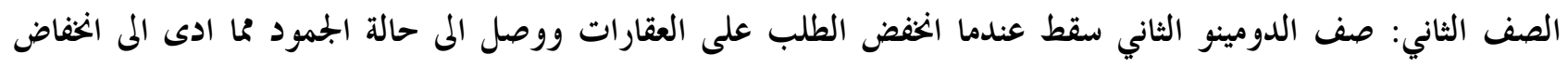

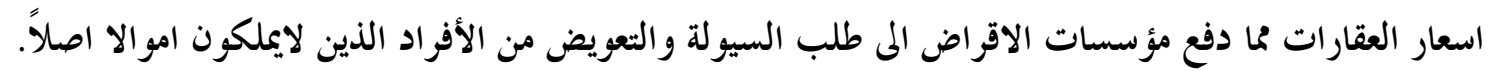

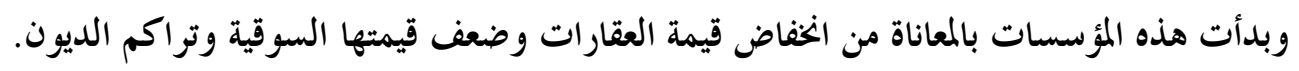

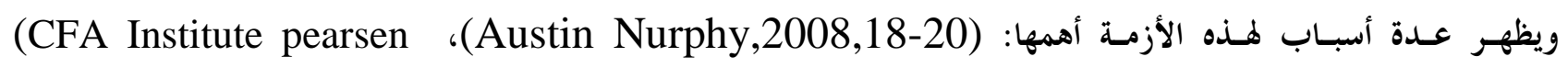
(Martin Zistter,2010,78- ،(The Global Financial Crisis,140-141)،custom Pulisting,2008,11) (www.kantakji.con/fiqh/files/ Economic/11018.doc) ،86) 
ا ـ تراخي الرقابة المالية الوقائية الحكومية على المصارف والمنظمات وخاصة في غياب الرقابة من قبل البنك المركزي الامريكي

$$
\text { على البنوك الاستثمارية. }
$$

r. اضطرابات في القطاع المالي بسبب توسع حجم الائتمان وانهيار الاسواق المالية، إذ زاد حجم الائتمان ومنح القروض

$$
\text { العقارية التي كانت السبب الرئيسي وراء هذه الازمة الامريكية والتي اصبحت ازمة مالية. }
$$

r. عدم استقرار الاقتصاد الكلي مثل التقلبات فباسعار الفائدة العالمية اذ يظهر اثرها واضحا وصعبا في الدول النامية. ع. يقوم النظام المالي ونظام الاسواق المالية على نظام المشتقات المالية التي تعتمد على تعاملات وهمية ورقية وشكلية للعديد من

المبادلات الفعلية للسلع والخدمات.

ه. التوسع والافراط بضمان البطاقات الائتمانية بدون رصيد (السحب على المكشوف) وطرح ادوات استثمار غير مفهومة من قبل الأفراد والمؤسسات مما أدى المى تحمل تكاليف عالية وهذا سبب رئيس لظهور الازمة واصبح عدم قدرة الأفراد والشر كات لتسديد ديونهم مما ادى المى الحجز على سياراتهم ومنازلمم ، فدارت الازمة في دائرة مفرغة نتيجة اضطرار الأفراد والشر كات المى بيع عقاراتهم فهبطت قيمتها وزاد العرض عن الطلب في مجال العقارات وانخفض الانفاق الاستهلاكي والاستثماري وضعفت قدرة البنوك في تمويل الشركات والأفراد وتهاوت المؤسسات وانهارت وافلست البنوك مما هدد

$$
\text { بالاقتصاد الامريكي بظهور حالة الكساد الصعب. }
$$

7 . استخدام سئ للمشتقات المالية من خلال وجود اقراض واسع يفوق الحاجة الحقيقية له. V. الوقوع في اخطاء السياسة الاقتصادية من خلال تشجيع الاستهلاك بدون حدود. ^. مطالبة شر كات الاستثمار العقاري المقتزضين بتسديد القروض قبل مواعيدها الخددة من اجل توفير السيولة في ظل ظهور الازمة من لجأ المقزضين ببيع عقاراتهم من أجل التسديد وكان هذا البيع فوق طاقة قدرة السوق العقارية مما ادى المى هبوط

$$
\text { في قيمتها بشكل كبير. }
$$

9. عدم تنويع الضمانات المقبولة لقاء التسهيلات المصرفية المقدمة من قبل المصارف والزكيز على الضمانات العقارية وعدم

$$
\text { وجود حدود لتملك المصارف للعقارات او التسليف لشراها. }
$$

• 1 . قيام النظام المالي والمصرفي بنظام جدولة الديون بسعر فائدة اعلى او استبدال قرض واجب السداد بقرض جديد بسعر فائدة مرتفع وهذا يلقي اعباء اضافية على المقزض الذي عجز عن تسديد القرض الاول وسوف يتحمل القرض الثاني بسعر فائدة

11 ا نظرية الو كلاء وطمع المصارف والمدراء الذين يديرون هذه المصارف فيسبقون مصالحهم الخاصة على مصلحة الملاكين لها وهذه النظرية جعلت من فصل ملكية رأس المال للشركة وعملية الرقابة والاشراف داخل الشر كات والمصارف واصبح المدير 
(الوكيل) متخذ القرار ويعمل لصاح المالك، وكان هذا سبب رئيسي لحدوث الازمة لكون المدير يعمل لصالحه وليس لصاح المالك وحلة الاسهم.

با. عدم تماثل المعلومات اصبحت المعلومات التي لدى المصارف والشر كات مغايرة عن المعلومات للأفراد والشركات الاخرى

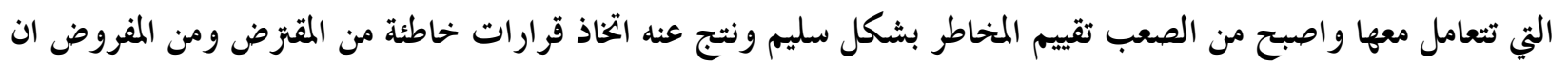
تكون المعلومات واضحة وكاملة وسليمة عن الأفراد والشركات المقزضة من المصارف من اجل اتمام عقد القرض بين الطرفين لضمان سلامة القرض واستز جاعه والقدرة على سداده.

با 1. العجز الثؤام بين الميزان التجاري وميزانيتة العامة حيث ان العجز التجاري بسبب ارتفاع حجم الاستيرادات الامريكية من الصين والهند والدول الاسيوية.

ـ ا. الحروب السريعة التي خاضتها الولايات المتحدة في الصومال ويوغسلافيا والعراق وأفغانستان والتي كلفت الولايات المتحدة ثلاثة تريليون دولار.

\section{سادساً. الحالات المسبة لازمة الرمن العقاري}

الأسباب لأزمة الرهن العقاري عديدة ومتنوعة البعض منها سببها الأفراد والشركات والبعض الاخر سببها البنوك والمصارف المارف

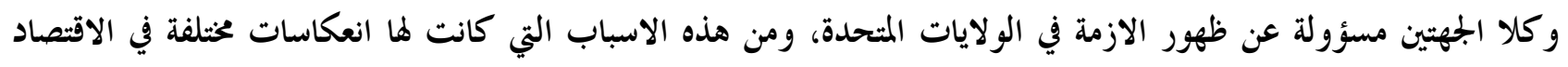

$$
\text { الامريكي واقتصاديات العالم أبرزها: }
$$

1. انخفاض اسعار النفط والمواد الغذائية للبلدان المصدرة لها واللجوء المى التمويل بالعجز.

r. . ارتفاع اسعار الفائدة على الاقززاض واصبح من الصعب امكانية الحصول على القروض بالتسهيلات المعروفة عنها. ب. استحداث وسائل وادوات الرقابة المصرفية الحديثة .

ع. الاندماج والانضمام بين المصارف وافلاس بعضها الآخر ومنها اكبر مصارف الولايات المتحدة (ليمان براذر). ه. اعتماد السيولة كمعيار للاداء المالي ،ومنها كفاية رأس المال . ج. انشاء نظام لادارة المخاطر في المصارف بأعتباره صمام الامان ووسيلة الانذار المبكر للازمات. V. تراجع قيمة الموجودات في البورصات العالمية تقريبا النصف وخسارة كبيرة للمستثمرين والمضاربين في محافظهم الاستثمارية. ^. زيادة المخاطر المالية بسبب ضعف القدرة على التنبؤ. 


\section{المبحث الثاني

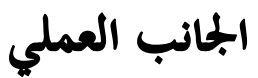

أولاً. تفسير مؤشرات البحث

إن مؤشر قوة رأس المال في المصارف ضروري جدا لسلامة المصرف وتدعيم الثقة فيه، ولكن المصرف لا يضمن تلك السلامة

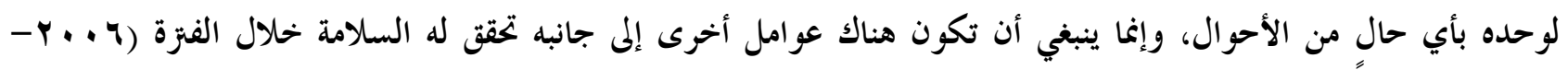

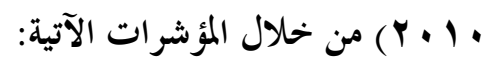

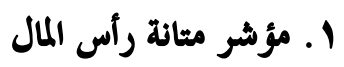
الذي يعبر عن المعادلة الرياضية الآتية:

مؤشر متانة رأس المال= $\quad$ مجموع الحسبة رأس المال + الاحتياطية
Y ب. نسبة رأس المال الممتلك إلى الودائع تشير هذه النسبة إلى مدى مقدرة المصرف على رد الودائع من رصيد رأس المال الممتلك.

$$
\text { نسبة رأس المال الى الودائع = }
$$

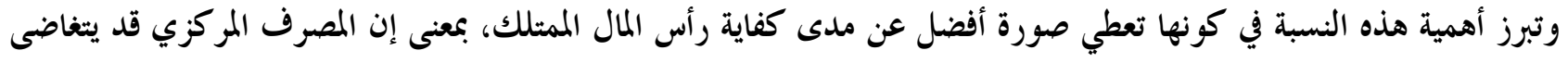

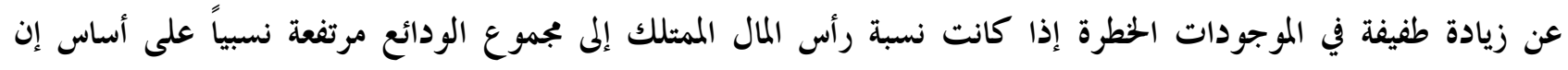

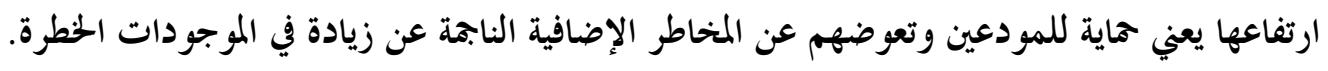

با ب. مؤشر الربحية

تشير هذه النسبة إلى فاعلية الموجودات في توليد الأرباح وتدل على قدرة المصرف على استغلال الموجودات وتوليد الأرباح،

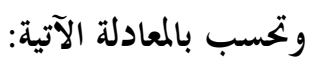

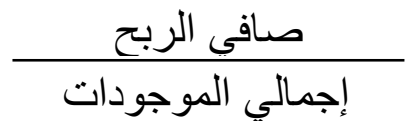

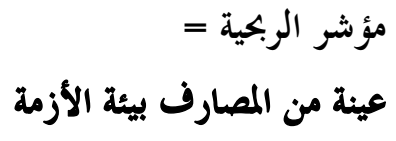

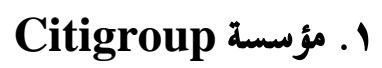

تعد هذه المؤسسة مؤشراً للوعود بعيدة المنال والعثرات المتعددة للقطاع المصرفي الدولي، وإذ قمنا بتحليل هذه المؤسسة بالاعتماد

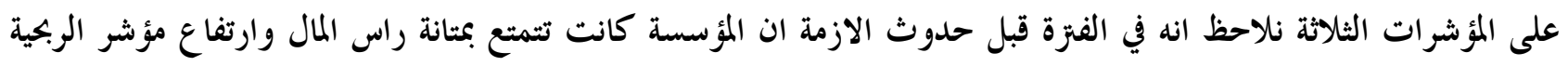

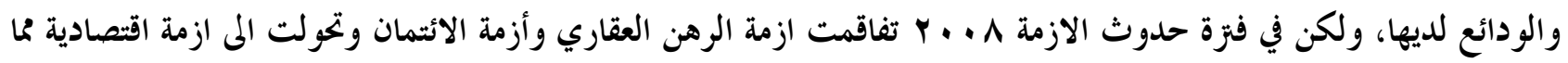

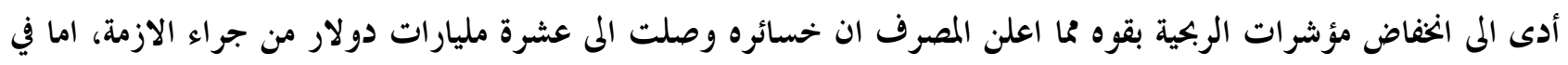
الفزة بعد وقوع الازمة نلاحظ ارتفاع المؤشرات الثلاثة.

$$
\text { الجدول (Y-1) }
$$




\section{Citigroup المؤشرات المالية لمؤسسة}

\begin{tabular}{|c|c|c|c|c|c|}
\hline 2010 & 2009 & 2008 & 2007 & 2006 & Citigroup \\
\hline 0.25 & 0.22 & -0.14 & 0.27 & 0.21 & مؤشر الربحية \\
\hline 10.7 & 9.60 & 2.30 & 5.02 & 7.47 & مؤشر مثانة رأس المال \\
\hline 1.27 & 1.12 & 0.11 & 1.29 & 0.16 & ؤشر الوداثع \\
\hline
\end{tabular}

المصدر: الجدول من إعداد الباحثتين بالاعتماد على القوائم والتقارير المالية.

\section{Bank of America ro مؤسسة}

تمثل هذه المؤسسة ثاني اكبر المصارف التجارية في الولايات المتحدة الامريكية من حيث القيمة السوقية، كما انها اكبر مصرف

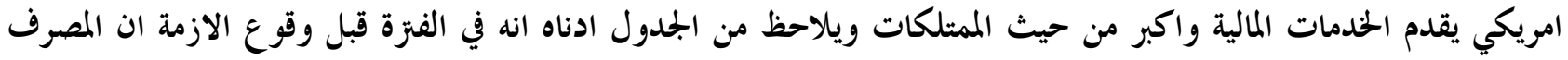
كان يتمتع بمتانة راسمال جيدة حيث كان ملتزمأ بتعليمات لجنة بازل فضلاً عن تحقيق المصرف للربحية ، اما في فنزة حدوث المات الازمة A . . P نلاحظ الخفاض المؤشرات الثلاثة فقد كانت سنة في غاية الصعوبة على المصرف، اما في فنزة وقوع الازمة فنلاحظ ان المصرف استعاد نشاطه فقد عمل على تعزيز متانة راس المال فضلاُ عن ارتفاع نسبة الربحية لدى المصرف وزيادة مؤشر الودائع. الجدول (r-r

Bank of America المؤشرات المالية لمؤسسة

\begin{tabular}{|c|c|c|c|c|c|}
\hline 2010 & 2009 & 2008 & 2007 & 2006 & Bank of America \\
\hline 0.88 & 0.38 & 0.22 & 0.87 & 0.44 & مؤشر الربحية \\
\hline 8.60 & 7.81 & 5.15 & 6.87 & 8.64 & مؤهر متانة رأس المال \\
\hline 0.19 & 1.81 & 0.15 & 1.36 & 0.17 & مؤشر الوداثع \\
\hline
\end{tabular}

المصدر: الجدول من إعداد الباحثين بالاعتماد على القوائم والتقارير المالية.

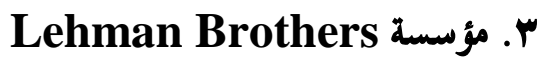

تعد هذه المؤسسة رابع اكبر مصرف في الولايات المتحدة الامريكية، وقد اعلن عن افلاسه اذا انخفضت قيمة أسهمه نبسبة ؟ ؟ ؟

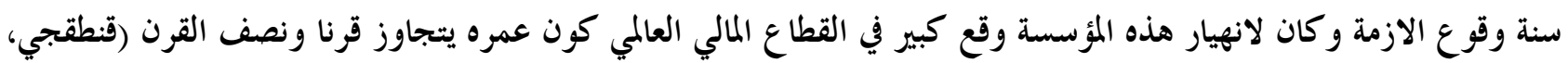

.$(T V, Y \cdots A$

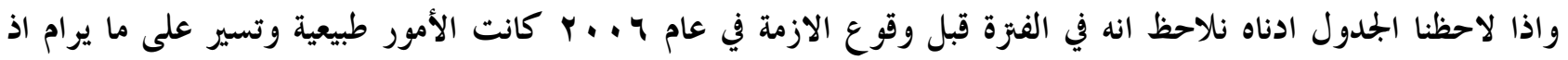
ظهرت بوادر الازمة في عام V. . . اذ اذ انخفض مؤشر متانة راس المال الم النصف تقريبا وانخفض مؤشر الربحية ومؤشر الودائع،

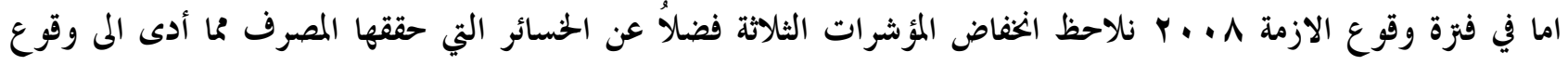

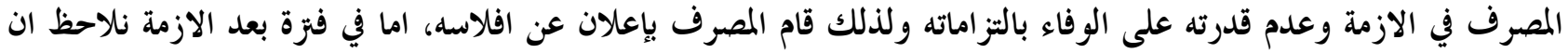

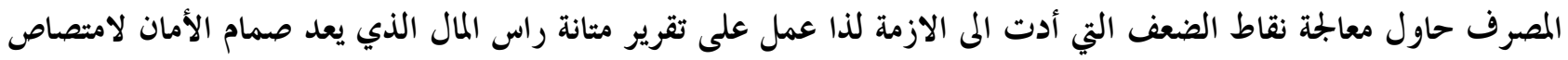

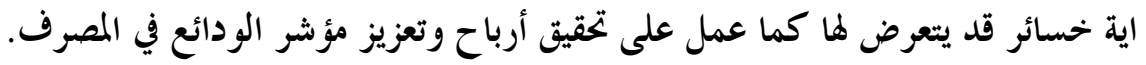
الجدول (Y-r) 


\section{Lehman Brothers المؤشرات المالية لمصرف}

\begin{tabular}{|c|c|c|c|c|c|}
\hline 2010 & 2009 & 2008 & 2007 & 2006 & Lehman Brothers \\
\hline 0.81 & 0.27 & -0.35 & 0.60 & 0.80 & مؤشر الربية \\
\hline 15.8 & 16.6 & 0.54 & 2.11 & 4.20 & مؤشر مثانة رأس المال \\
\hline 0.24 & 0.20 & 0.10 & 0.17 & 0.23 & مؤشر الودائع \\
\hline
\end{tabular}

المصدر: الجدول من إعداد الباحثين بالاعتماد على القوائم والثقارير المالية.

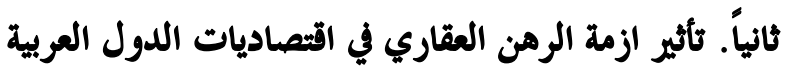
بروز أزمة الرهن العقاري وتطورها اقليميا ودوليا يضع امامنا العديد من الاشكاليات الاقتصادية والاجتماعية والمالية الصعبة تتعارض والسياسات الانمائية والتكاملية في كل دول العالم معرقلة مسيرتها الاقتصادية واستقرارها وتلك الاشكاليات المتمثلة بالبطالة والتضخم والكساد والديون. وامتدت هذه الازمة والقت بظلالها على اقتصاديات الدول العربية بشكل مباشر وغير مباشر من خلال امتداد شحة السيولة في اسواقها ومصارفها مما ادى المى ظهور ازمة السيولة في مصارف الدول العربية بعد اعلان افلاس بنك الاستثمار Leman أف brothers في الدول المتقدمة من اجل اعادة بناء قاعدة رأسمالية للمصارف الرئيسية (الام) وخاصة ان الاموال المودعة في المقر الرئيسي لهذه المصارف بالعملة الاجنبية مما ادى المى خروج رؤوس اموال كبيزة من اسواق واقتصاديات الدول العبية مما جعل زعزعة في استقرار النظام المصرفي لعدد من هذه الدول.

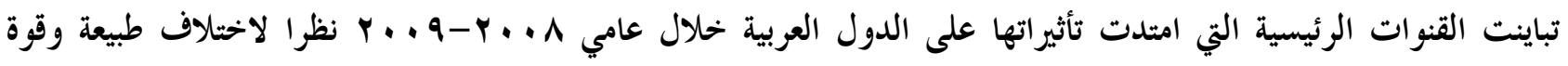
اقتصادها ومدى درجة انفتاحها وارتباطها مع الاقتصاد العالمي: فبالامكان تصنيف هذه الاقتصادات المى ثلاث مجموعات: (إدارة البحوث والدراسات الاقتصادية، مجلس الغرف السعودية

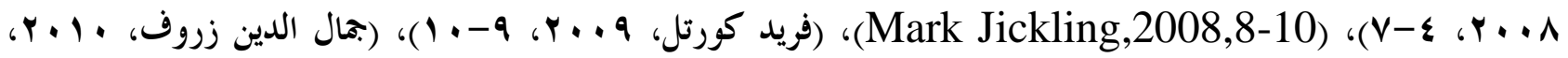
. $\left(\right.$ $\wedge-r^{\circ}$ الجموعة الأولى: دول الخليج العربي التي تتسم بالانفتاح والارتباط الواضح والكبير مع اقتصادات العالم وخاصة الارتباط مع سوق الاوراق المالية العالمية، فضلاً عن ذلك تعد من الدول المنتجة والمصدرة للنفط الحام والغاز والبتزو كيمياويات (دول نفطية) فيظهر من هذا التأثير الكبير والعدوى الواضحة للازمة في اقتصادياتها مما جعل التذبذب الكبير في سوق الاوراق المالية الخليجية بالارتفاع والانخفاض الشديد والانتكاسات والتأثير الواضح في ميزانيتها نتيجة الانخفاض المفاجئ في اسعار النفط والانخفاض في الايرادات النفطية التي تشكل الاساس في ايراداتها العامة. وخاصة ان هذه الدول قبل ازمة الرهن العقاري اصبح لديها فوائض مالية كبيرة نتيجة ارتفاع الكبير في اسعار النفط وتدفقات رأسمالية كبيرة لتمويل المشروعات الضخمة الموجودة في العديد من الدول وخاصة الولايات المتحدة واليابان والاتحاد الاوربي وتوسع كبيز في الائتمان المصرفي للقطاع الخاص. 
وبحلول الازمة المالية وتفاقمها وعدواها المى هذه الدول حصل تقلص كبير بالفوائض المالية وانخفضت السيولة لدى المصارف والقطاع الخاص وضعفت ثقة المستثمرين نتيجة الاوضاع الاقتصادية الخلية وانخفض التمويل للمشروعات الكبيرة وحصل ازمة دين في مؤسسات القطاع الخاص وثم تأجيل وتجميد العديد من المشروعات وخاصة المشروعات العقارية.

إذ قدرت بحوالى هVه مليار دولار مقارنة مع اجمالي المشاريع التي كانت قيد التنفيذ بحوالى ه, ج تريليون دولار في نهاية A . . Y، مما ادى المى تراجع الطلب الخلي على العقارات وانخفضت اسعاره واثرث على قيمته فأحذت المصارف بالحذر وركزت على القواعد الرأسمالية لها ووضع المصارف شروط صعبة في الاقراض مما ادى المى تراجع حجم الائتمان المصرفي لديها. الجموعة الثانية: الدول التي لديها اسواق مالية محلية مرتبطة بشكل مباشر مع الاسواق المالية العالمية وهذه الدول ايضا تعد من الدول النفطية ومرتبطة بأسعار النفط العالمي وايراداتها وميزانيتها ترتفع وتنخفض مع ارتفاع والخفاض اسعار النفط، وهذه الجموعة تأثرها اقل من الجموعة الاولى لكونها اكثر انغلاقا على العالم الخارجي وغير مرتبطة ماليا ومصرفيا بالسوق العالمي وليس لديها اسواق مالية واسعة ومفتوحة بتعاملاتها وليس لديها شركات واستثمارات في الدول المتقدمة بسبب انغلاقها على الاستثمار الاجني لكن تأثرت نتيجة التذبذب في اسعار النفط وانخفاض حجم الحصص بالانتاج وحجم الصادرات النفطية مما اثر على اقتصادها الخلي نتيجة انخفاض حجم ايراداتها فتباطئ النشاط الاقتصادي لمعظم قطاعاتها الصناعية والزراعية والخدمية والتباطئ الواضح في تنفيذ مشاريع البنية التحتية لديها. البجموعة اليالةة: الدول العربية التي لديها علاقات تجارية وتعتمد على الاستيرادات والاقتزاض الخلي فهي دول تكون بعلاقة غير مباشرة مع الولايات المتحدة والاتحاد الاوربي وتقتصر العلاقة فقط في مجال المعاملات السلعية كالاستيرادات وبقطاع السياحة والثحويلات المالية والتدفقات الاستثمارية الاجنبية فأي أزمة او تباطئ يحصل في الولايات المتحدة ودول اوربا تتأثر اقتصادياتها من خلال تراجع معدلات السياحة والعلاقات التجارية والتحويلات المالية، ففي فنزة الركود والكساد التي حصل بالولايات المتحدة بسبب ازمة الرهن العقاري اثر بشكل واضح على ايراداتها من حيث ايرادات القطاع السياحي ومن حيث الصادرات والواردات السلعية والتحويلات المالية وتدفقات الاستثمار الاجنيي لديها، وفيما يلي ابرز المؤشرات المالية والاقتصادية وكما

يأتي: يتضح من الجحول (ع - (1) الذي يوضح أسعار النفط لدول الخليج (السعودية وقطر والامارات) والعراق ومصر خحلال السنوات

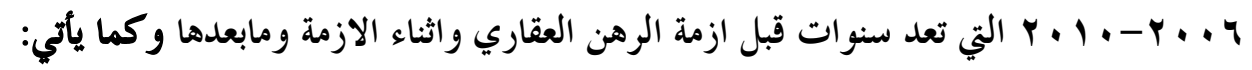




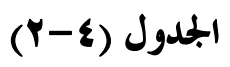

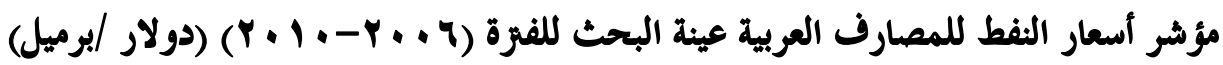

\begin{tabular}{|c|c|c|c|c|c|c|c|c|c|c|}
\hline$r \cdot 1$. & $r \cdot q q$ & متو سط & الربع الربع & الثالث & الثاني & الربع & $r \cdots v$ & $r . . T$ & مؤشر أسعار النفط & ت \\
\hline$\vee \vee, \Lambda$ & $71, \varepsilon$ & $q \bullet, r$ & ץ॰, & r & $11 \wedge, V$ & 94,1 & $\checkmark \Lambda, V$ & 71,1 & السعودية (العربي الحخفيف & 1 \\
\hline$\vee \wedge, r$ & $\neg Y, \varepsilon$ & $9 \varepsilon, 9$ & or, q & $11 \varepsilon, V$ & 118,7 & $q r$, & $7 \wedge, 9$ & $Y Y, Y$ & قطر & $r$ \\
\hline$\vee q, q$ & וץ, & 99, & oV, r & 119,7 & Irr, q & 97,1 & $V r, q$ & 74,1 & $\begin{array}{c}\text { الامارات (خام مربان } \\
\text { الاماراتي) }\end{array}$ & r \\
\hline$V q, V$ & $7 \cdot, 0$ & qr, 1 & or, q & $11 \cdot r$ & $11 \varepsilon, V$ & $q \cdot, \varepsilon$ & 77,8 & $\bullet \wedge$, & 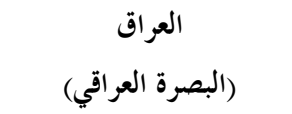 & $\varepsilon$ \\
\hline$V \bullet, \varepsilon$ & $\bullet \wedge, \Lambda$ & $q r, V$ & or,r & $11 \%, 0$ & $11 \varepsilon$, & $q 1, r$ & $77, V$ & 09,1 & مصر (خليط السويس & 0 \\
\hline
\end{tabular}

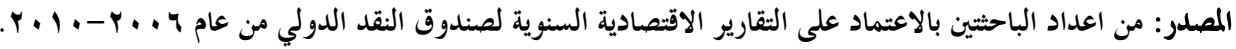

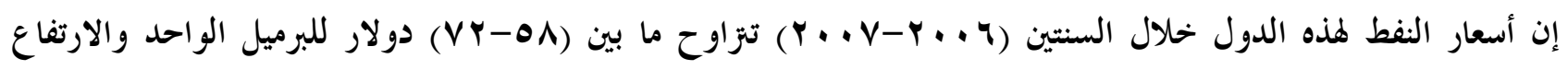

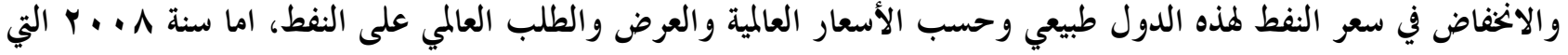

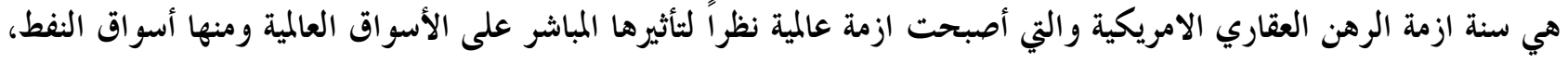

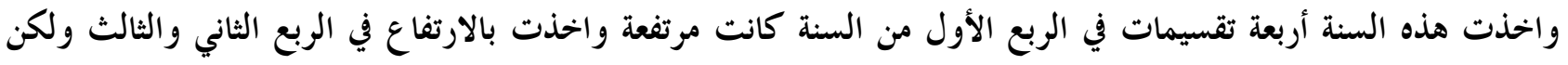

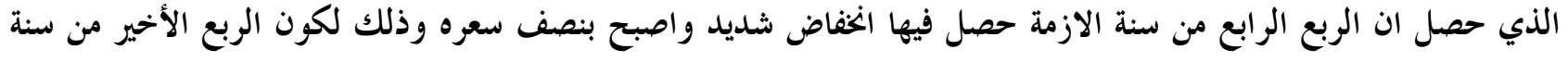

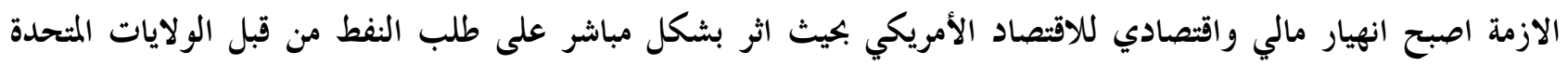

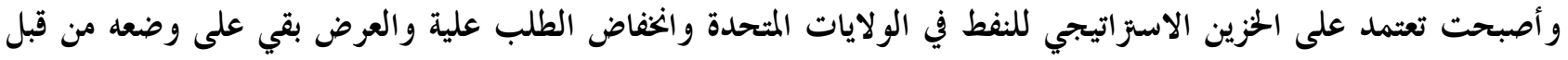

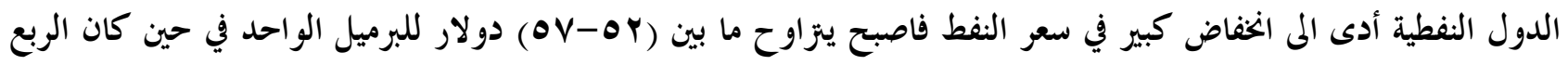

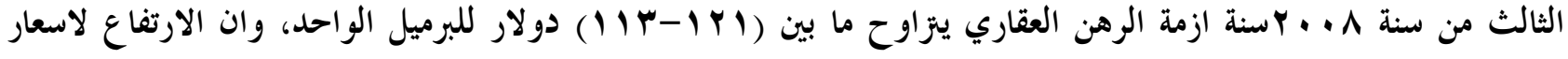

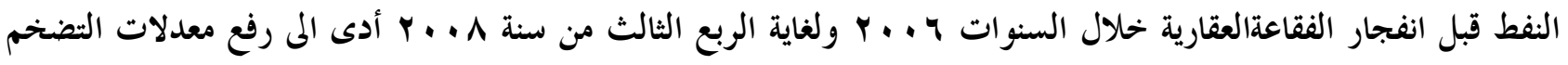

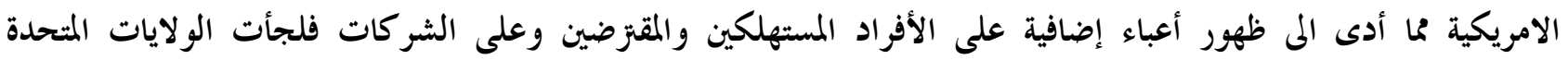

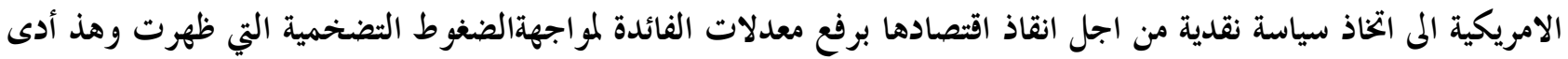

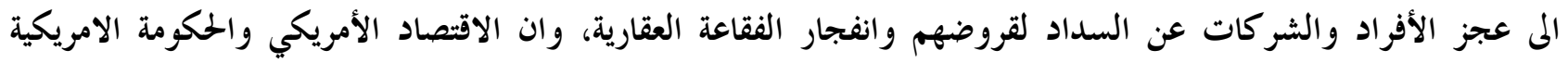

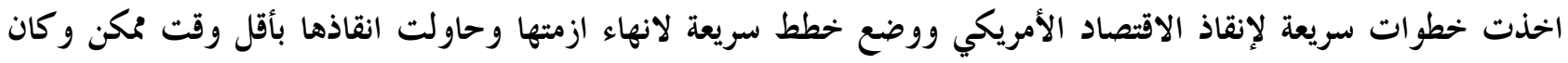

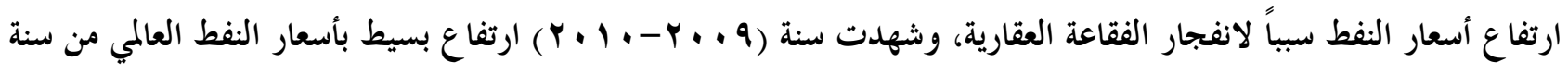

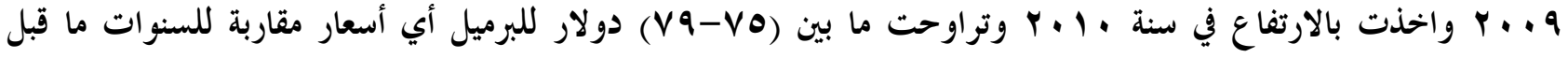




\section{ثانياً. مؤشر سوق الأوراق المالية}

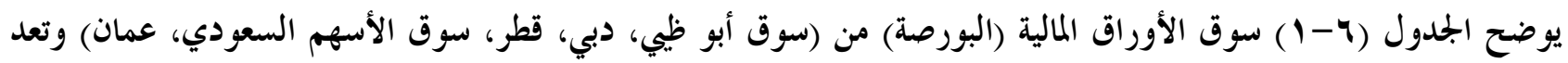

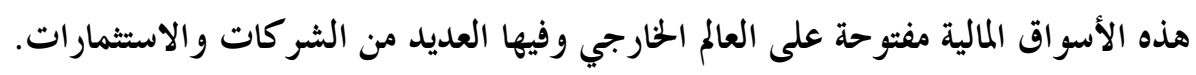

$$
\text { الجمدول (Y-0) }
$$

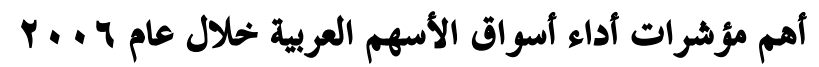

\begin{tabular}{|c|c|c|c|c|}
\hline معدل دوران الأسهم\% & للاسهم في الاقتصاد * القيمة السوقية & عدد الشركات & السوق/البورصة & ت \\
\hline$r \mu, \Lambda$ & $r \cdot \Lambda, 0$ & 9. & سوق أبو ظيي للأوراق المالية & 1 \\
\hline 1.9 & Or,T & $\leq 4$ & سوق دبي المالي & r \\
\hline ( ו ו & 110,0 & rq & بورصة قطر & $r$ \\
\hline$\varepsilon r q, r$ & $q \leq, Y$ & 19 & سوق الأسهم السعودي & $\varepsilon$ \\
\hline$V Y, V$ & $r \cdot \Lambda, 0$ & TYV & بورصة عمان & ○ \\
\hline or,r & $\Lambda v, 1$ & $7 . r$ & البور صة المصرية & 9 \\
\hline
\end{tabular}

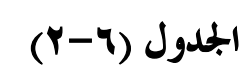

\begin{tabular}{|c|c|c|c|c|}
\hline معدل دوران الأسهم\%\% & ألاسمية القيمة السوقية & عدد الشر كات & السوق/البورصة & ت \\
\hline$r q, \varepsilon$ & (4,1 & $7 \varepsilon$ & سوق أبو ظيي للأوراق المالية & 1 \\
\hline$V \varepsilon, \Lambda$ & $V_{r}, \cdot$ & 00 & سوق دبي المالي & r \\
\hline$r, r$ & $1 \leqslant 9, \varepsilon$ & $\varepsilon$. & بورصة قطر & $r$ \\
\hline$|r|, \varepsilon$ & ITV, & 111 & سوق الأسهم السعودي & $\varepsilon$ \\
\hline$\varepsilon r, r$ & $Y \cdot ४, \varepsilon$ & $r \leqslant 0$ & بورصة عمان & 0 \\
\hline$\varepsilon V, r$ & $1 \cdot \wedge, 0$ & \&To & البورصة المصرية & 7 \\
\hline
\end{tabular}

أمم مؤشرات أداء أسواق الأسهم العربية خحلال عام V...

* القيمة السوقية للاسهم على الناتج الخلي الإجمالي.

المصدر: من اعداد الباحثين بالاعتماد على التقارير الاقتصادية السنوية لصندوق النقد الدولي عام V . . . . 


\section{الجدول (Y-V)}

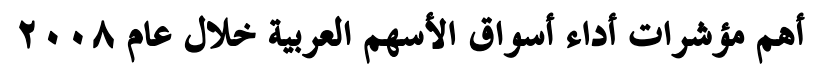

\begin{tabular}{|c|c|c|c|c|}
\hline معدل دوران الأسهم\% & للاسهم في الاقتصادة القيمة السوقية & عدد الشركات & السوق/البورصة & ت \\
\hline $91, v$ & - & 90 & سوق أبو ظيي للأوراق المالية & 1 \\
\hline$|r|, v$ & - & 90 & سوق دبي المالي & $r$ \\
\hline 74,9 & $V \varepsilon, 9$ & $\varepsilon r$ & بورصة قطر & $r$ \\
\hline$r \mid r, r$ & or,v & IYV & سوق الأسهم السعودي & $\varepsilon$ \\
\hline$\Lambda \cdot, \cdot$ & $1 \wedge, \wedge$ & rat & بورصة عمان & 0 \\
\hline $1 \cdots, 7$ & Or, & rVr & البورصة المصرية & 9 \\
\hline
\end{tabular}

* القيمة السوقية للاسهم على الناتج الخلي الإمحالي.

المصدر: من اعداد الباحثتين بالاعتماد على التقارير الاقتصادية السنوية لصندوق النقد الدولي عام ^ ـ . r. الجدول (Y-人)

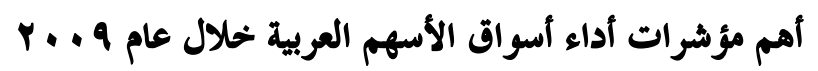

\begin{tabular}{|c|c|c|c|c|}
\hline معدل دوران الأسهم\% & ألاسمية القيمة السوقية & عدد الشركات & السوق/البورصة & ت \\
\hline$r \Delta, r$ & $\Lambda \cdot, r \cdot 1$ & IV & سوق أبو ظيي للأوراق المالية & 1 \\
\hline VA & $01, .90$ & IV & سوق دبي المالي & $r$ \\
\hline$r \cdot, \Lambda$ & AV,qr. & $\varepsilon \varepsilon$ & بورصة قطر & $r$ \\
\hline 119 & rA,V०1 & iro & سوق الأسهم السعودي & $\varepsilon$ \\
\hline$\varepsilon \cdot r$ & $r, \wedge \wedge q$ & TVY & بورصة عمان & 0 \\
\hline $91, v$ & $91, .94$ & $r .9$ & البورصة المصرية & 9 \\
\hline
\end{tabular}




$$
\text { الجمدول (r-q) }
$$

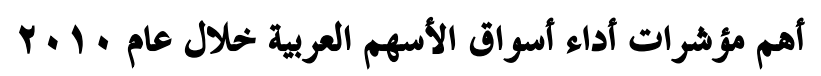

\begin{tabular}{|c|c|c|c|c|}
\hline معدل دوران الأسهم\% & لكلاسهم في الاقتصاد القيمة السوقية & عدد الشركات & السوق/البورصة & ت \\
\hline $11, \varepsilon$ & $V V, \cdot A l$ & $7 \varepsilon$ & سوق أبو ظيي للأوراق المالية & 1 \\
\hline r^,O & $0 \leqslant, 79 Y$ & 90 & سوق دبي المالي & r \\
\hline IV, $\varepsilon$ & $\mid r r, Y \leq 1$ & $\varepsilon r$ & بورصة قطر & $r$ \\
\hline$r \cdot, r$ & ror, \&.. & $1 \leqslant 4$ & سوق الأسهم السعودي & $\varepsilon$ \\
\hline $1 \wedge, r \leq$ & $r \cdot, q \cdot \varepsilon$ & TVV & بورصة عمان & 0 \\
\hline $10, V$ & $\Lambda \varepsilon, 1.9$ & rir & البورصة المصرية & 9 \\
\hline
\end{tabular}

* القيمة السوقية للاسهم على الناتج الخلي الإمحالي.

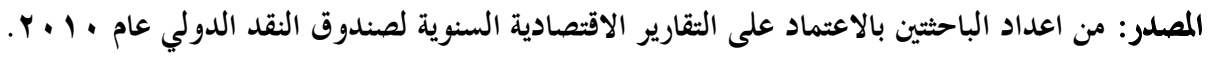

1. سوق أبو ظي للأوراق المالية: عدد الشركات فيها يتزاوح ما بين . ج-VI شركة وباستثمارات مختلفة، فالقيمة السوقية

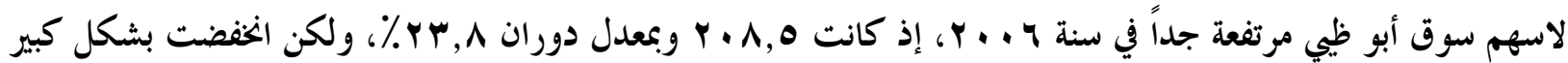

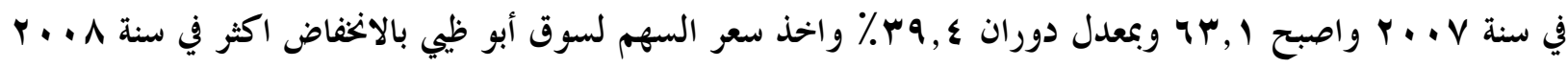
(أزمة الرهن العقاري) واصبحت بععدل دوران كبير جداً V, 19٪ وهذا يعني ان انفجار الازمة العقارية خلقت التوقعات

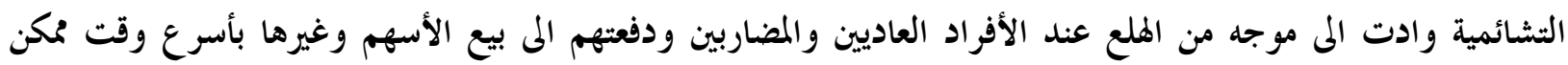
لتجنب الحسائر الختملة التي أدت المى الانهيار والزز اجع الاقتصادي والمالي للسوق المالي ولاقتصاد الدول.

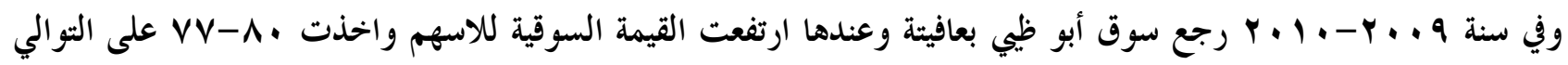

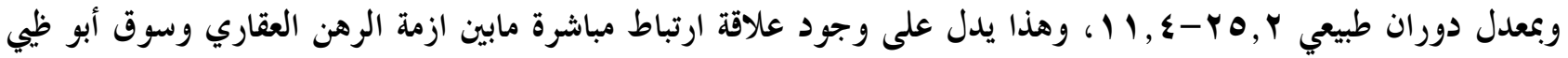
كلأوراق المالية والثاثير المباشر فيه.

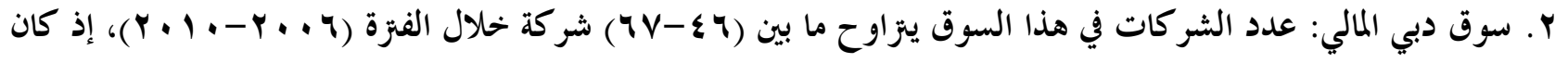

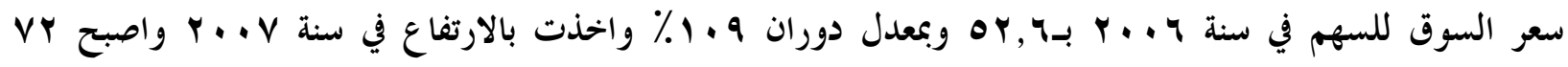
وبعمدل دوران ع ٪\% ولكن لما عصفت ازمة الرهن العقاري الأسواق المالية في العالم أدى المى انخفاض القيمة السوقية للسهم

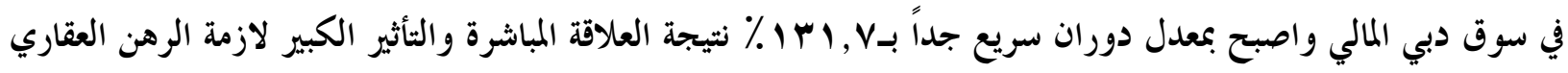

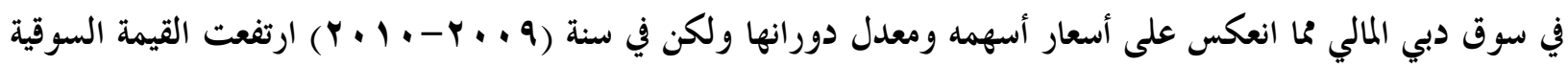

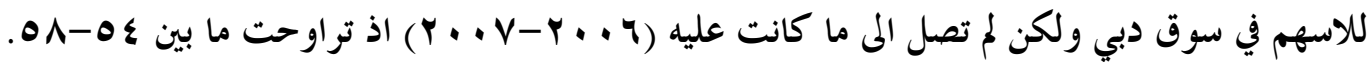


r. سوق قطر: عدد الشركات المساهمة في بورصة قطر تراوح بين ؟س-ع ع شركة ولكن القيمة السوقية لاسهم هذا السوق

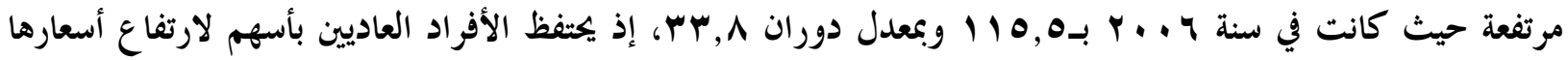

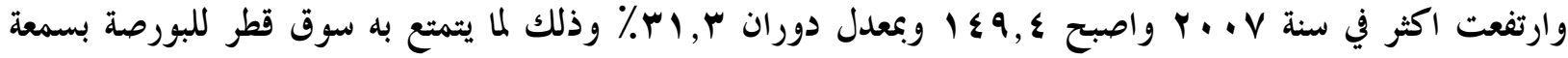
جيدة في سوق الأوراق العالمية وفيها نقطة جذب كبير للمستثمرين فيه، وحصل انفجار الفقاعة العقارية في أمريكا والارتباط الكبير بين الولايات المتحدة وقطر حيث انخفضت القيمة السوقية للاسهم بشكل ملحوظ واصبح ع و وبمعدل دوران مرتفع 9, צ ؟ ٪ تسارع المستثمرين وخاصة الأجانب منهم ببيع الأسهم للتخلص منها تحسباً لانخفض أكبر بالمستقبل ولكن في سنة q . . . بعدما انتهت ازمة الرهن وبشكل جزئي رجعت القيمة السوقية للاسهم في سوق قطر بالارتفاع قليلاً وأصبحت AV,q وبمعدل دوران منخفض قياسا عن سنة الأزمة ولكن زاد الارتفاع تدريجيا ليصبح بقيمة سوقية مرتفعة مقارنة بسنة V . . . . وبععدل دوران منخفض جداً وهذا يدل على التخلص من الاثار السلبية لازمة الرهن العقاري في سوق قطر ورجوع بـ المستثمرين والمضاربين للسوق.

ع. سوق الأسهم السعودي: عدد الشركات المساهمة في هذا السوق اخذت بالتزايد سنة بعد الأخرى خلال الفترة (؟ . . ؟-

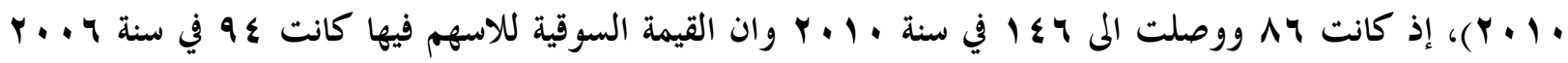

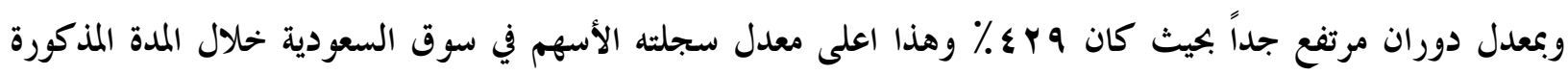
وبين الأسواق المالية لدول العينة واخذت القيمة السوقية للاسهم بالارتفاع في سنة V . . r ولكن بمعدل دوران اقل حيث

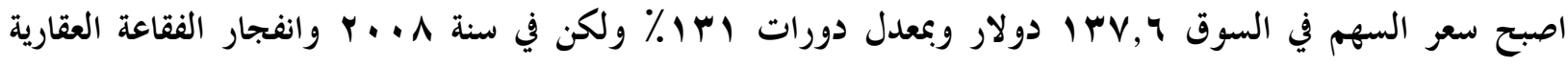
حصلت انخفاض شديد في القيمة السوقية للاسهم في السعودية واصبح بـ به دولار وبمعدل دوران مرتفع r ا ب\% للتخلص من الأسهم بسبب الانخفاض الكبير في قيمتة والعدوى الشديدة التي اصابت السوق المالي في السعودية واستمر الانخفاض في

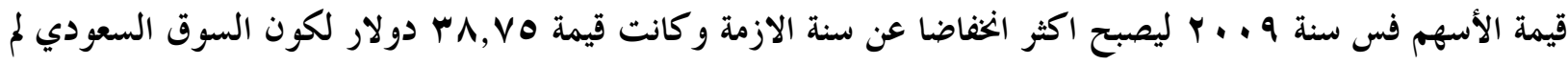
يتعافى من الازمة بشكل سريع قبل الأسواق المالية الأخرى، وهذا يعني ان معظم المستثمرين والمضاربين في السوق المالي السعودي من الولايات المتحدة ودول اوربا ولكن اصبح قفزة كبيرة في القيمة السوقية للاسهم في سنة • 1 . ل لتبلغ قيمته

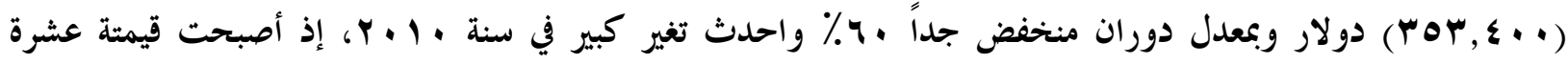

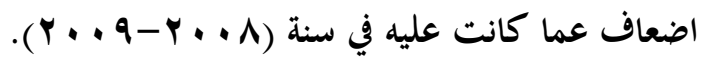

ه. بورصة عمان: في بورصة عمان عدد الشركات الداخلة في تعاملاته من اكثر دول العينة حيث يتزاوح بين (YVV-Y

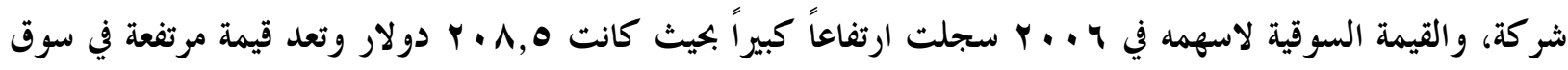

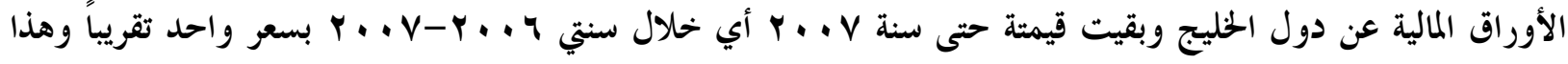
على وجود انتعاش واستقرار في بورصة عمان خلال الفتزة المذكورة ولكن في سنة ^ م. ․ الخفضت قيمتة بشكل كبير جداً 
بحيث اصبح ^1 دولار وهذا السوق اعلن خسارة كبيرة في تداولاته لتلك السنة بسبب ازمة الرهن العقاري وفي سنة

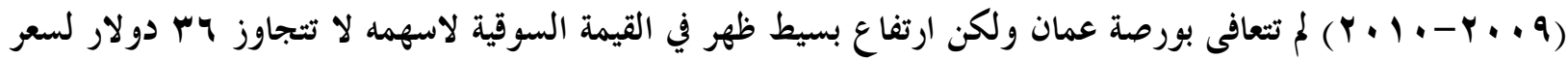

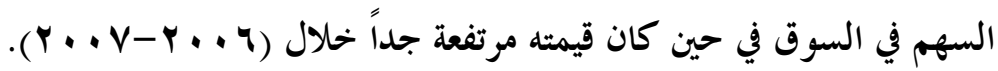

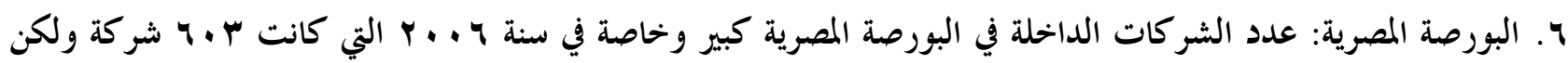

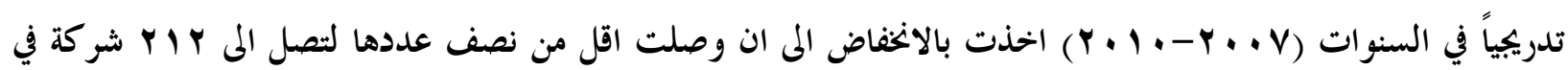
سنة • 1 • Y وهذا يعني ان البورصة المصرية اصبح فيها تباطئ في النشاط وانسحاب للعديد من الشركات وسجل اعلى

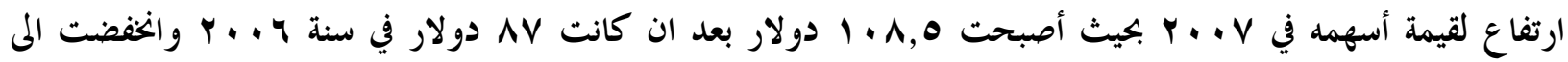

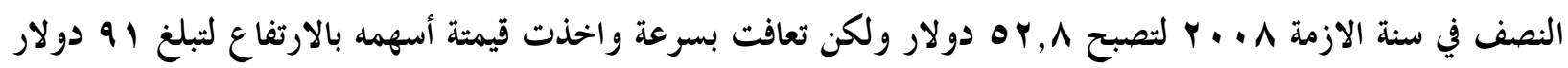

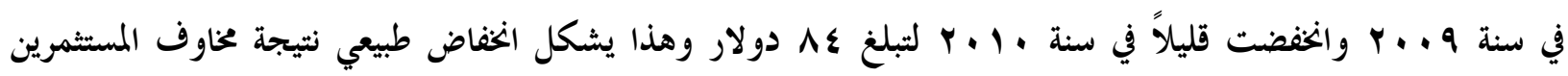
بسبب الأوضاع الأمنية التي مرت بها مصر خلال الفتزة المذكورة وانسحاب العديد من الشركات من البورصة المصرية. ثالهاً. مؤشر الناتج الخلي الإجمالي

$$
\text { ابلمدول (1) }
$$

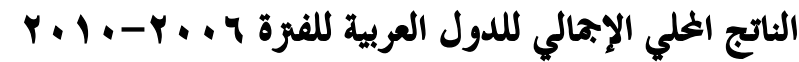

(مليون بالعملة الخلية)

\begin{tabular}{|c|c|c|c|c|c|c|}
\hline$Y \cdot 1$. & $r \cdot . q$ & $r \cdot A$ & $r \cdot r$ & $r \cdot . Y$ & الناتج الحلي الإجالي & ت \\
\hline $1,7 \vee 9,1 \cdot 9$ & $1, \& 17,097$ & $1, \vee \circ \wedge, \cdots 1$ & $1, \varepsilon \sim q, 010$ & 1, • & السعو دية & 1 \\
\hline$\varepsilon \neg \Lambda, \cdot \vee \wedge$ & 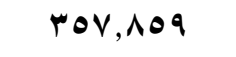 & 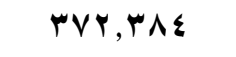 & Y०A,०91 & $Y \cdot \neg, 7 \leq \varepsilon$ & قطر & $r$ \\
\hline $1, \circ 94,11 \varepsilon$ & 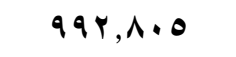 & $11,074,7 V$ & $9 \leq \Lambda, \diamond \neg$ & $\wedge \backslash 0, \Upsilon \wedge \varepsilon$ & الامارات & $\mu$ \\
\hline IN,VYr & $17,91 Y$ & $10,01,0$ & $17,07,9$ & $1 \cdot$, rVVA & الأردن & $\varepsilon$ \\
\hline $1, \varepsilon \varepsilon, \cdot Y \varepsilon$ & qه, • • & سץ & $91,1 \wedge v, \cdot v$ & $\Lambda \cdot, £ \diamond ৭, \varepsilon r r$ & العراق & 0 \\
\hline $1, r \cdot 7,7 r$. & $1, \cdot \varepsilon r, 100$ & $\wedge ৭ \neg, \varepsilon \neg \wedge, \vee$ & $\vee \varepsilon \varepsilon, V \wedge \vee$ & $\because 1 \vee, V \varepsilon \varepsilon$ & مصر & 7 \\
\hline
\end{tabular}

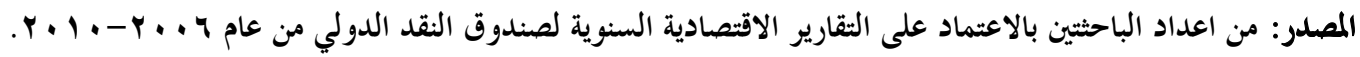

الناتج الخلي الإجمالي لكل دولة يمثل نشاط قطاعاته الاقتصادية العام والخاص وما انتجته من سلع وخدمات ومن الجدول ( . (-

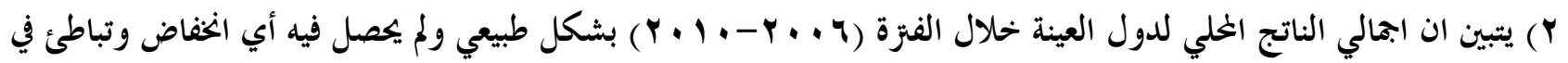

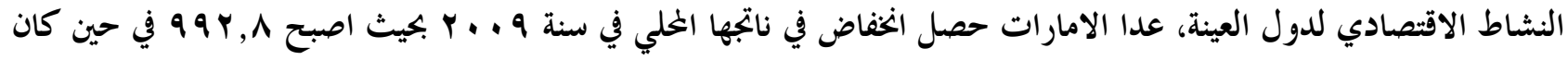

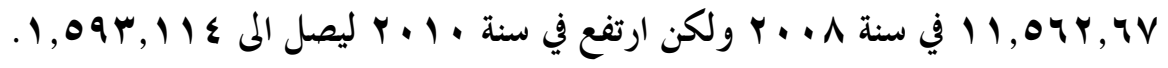
رابعاً. مؤشر الصادرت والواردات 
الجدول (1)

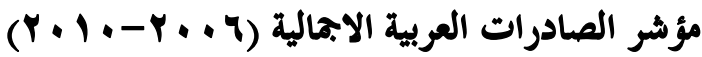

(مليون دولار)

\begin{tabular}{|c|c|c|c|c|c|c|}
\hline r. I. & $r \cdot . q$ & $r \cdot \wedge$ & $r \cdot r v$ & $Y \cdot r$ & مؤشر الصادرات & ت \\
\hline r & $r \cdot r, .0 r$ & rrr, $\cdot v i$ & 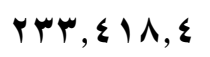 & $r \|, \cdot r r, \Lambda$ & السعودية & 1 \\
\hline$¥ 1,1 \wedge \wedge$ & $\varepsilon \theta, 9 \diamond \wedge$ & $7 V, \cdot \wedge q$ & rv, vq & $r q, 9 \wedge \cdot, 0$ & قطر & r \\
\hline$Y Y \varepsilon, \cdot r V$ & $r \cdot 1,909$ & $r \cdot r, r r r$ & $1 \Lambda \cdot, \wedge 9 \wedge$ & $1 r \varepsilon q 90, r$ & الامارات & $r$ \\
\hline$I Y, Y \cdot V$ & $17, \varepsilon \vee V$ & Ir, & $\varepsilon, \varepsilon \wedge \wedge, \diamond$ & $\varepsilon, 1 \mid \Psi, 7$ & الأردن & $\varepsilon$ \\
\hline$\Delta V, \leq 01$ & $\varepsilon 0, r \vee v$ & $\diamond \vee, \diamond \wedge \varepsilon$ & rq, $\varepsilon$. & $r q, r \varepsilon r, \cdot$ & العراق & 0 \\
\hline$\varepsilon 7,7 r \varepsilon$ & $\varepsilon V, \cdot \varepsilon r$ & •r,r. & $r \varepsilon, \varepsilon 0 \leqslant$ & $r \cdot, 0 \leq \theta, r$ & مصر & 7 \\
\hline
\end{tabular}

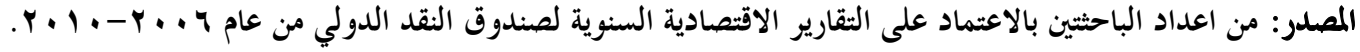

الجدول (Y-1Y

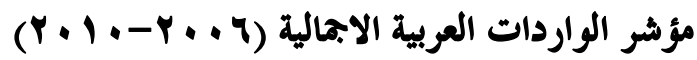

(مليون دولار)

\begin{tabular}{|c|c|c|c|c|c|c|}
\hline r. 1. & $r \cdot . q$ & $r \cdots \Lambda$ & $r \cdot . r$ & $r \cdot r r$ & مؤشر الواردات & ت \\
\hline$I V \varepsilon, r \cdot r$ & $174, .79$ & $1 \vee 7, \cdot \varepsilon \cdot$ & $9 \cdot, 107$ & $7 q, v \cdot v \cdot 1$ & السعو دية & 1 \\
\hline$r \varepsilon, \varepsilon q V$ & r., $79 r$ & r乏,Ar. & $r \cdot q r \varepsilon$ & $\mid r, 0 \ldots, \varepsilon$ & قطر & $r$ \\
\hline$r \cdot r, \wedge \varepsilon$ & 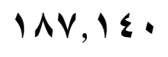 & 10\%,194 & $1 Y 1,100$ & $V V, \varepsilon 0 \leqslant, q$ & الامارات & $r$ \\
\hline $1 \vee, 9 \vee 0$ & $17, \varepsilon V V$ & $r \cdot, 9 \wedge r$ & IT, V० & $11,0 \leqslant \Lambda, r$ & الأردن & $\varepsilon$ \\
\hline$\varepsilon \varepsilon, 179$ & $\mu \wedge, \varepsilon \cdot \Lambda$ & $\varepsilon 1,1 \leq \Lambda$ & $r q, \cdot r \cdot$ & $r \bullet, r \otimes q, r$ & العراق & 0 \\
\hline 10, & 09,009 & $94,11 \mathrm{~V}$ & $r \cdot, \varepsilon \neg$. & $r r, 1 \cdot \varepsilon$, & مصر & 7 \\
\hline
\end{tabular}

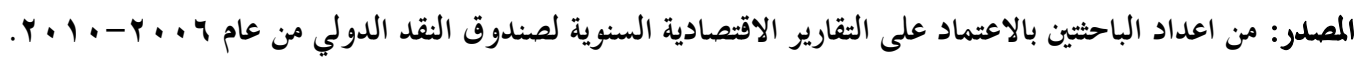

إن تدفقات الأموال بين الدول نتيجة التحرر التجاري المصاحب لظاهرة العولمة أدى المى مضاعفة حجم التجارة الدولية من السلع والحدمات، وان السوق الامريكية تعد من اكبر الأسواق العالمية من حيث الحجم والقوة الثرائية وان احصائيات الانكتاد تشير المى ان استيرادات الولايات المتحدة الامريكية تثثل • ب ٪ من اجمالي الاستيرادات العالمية وهذا يؤثر على نقل التغييرات في أسعار السلع والخدمات المتاجر فيها دوليا ويخلق ظاهرة نقل التضخم من والى الولايات المتحدة ودول العالم التي تقيم معها علاقات تجارية حيث تستورد التضخم من خلال الصادرات القادمة لها من الخارج ويصدر التضخم من خلال ماتستورده الدول الأخرى من الولايات المتحدة الامريكية. 
ومن الجدول يتضح ان السوق التجاري للسعودية من حيث الصادرات ارتفعت صادراتها في سنة V . . P عما كانت علية في

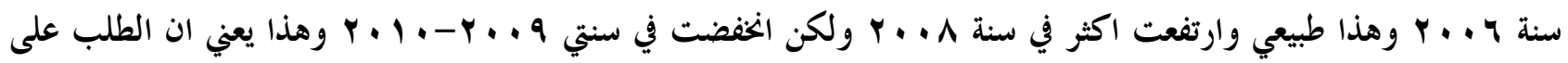
السلع من السوق السعودي سواء كان من النفط او منتجات وسلع أخرى اصبح اقل بعد ازمة الرهن العقاري في حين استيرادات السعودية من الدول الخارجية لم يتأثر ولكن اخذ بارتفاع طبيعي لكون الازمة لم تحصل في السعودية لذا استيراداتها لم تتاثر ولكن صادراتها تتأثر بسبب انخفاض الطلب العالمي على السلع المصنعة في السعودية سواء كانت مواد أولية أو نصف مصنعة.

كذلك الحال بالنسبة لدول العينة (قطر، الامارات، الأردن، العراق، مصر) صادراتها اخذت بالتزايد سنة بعد أخرى من

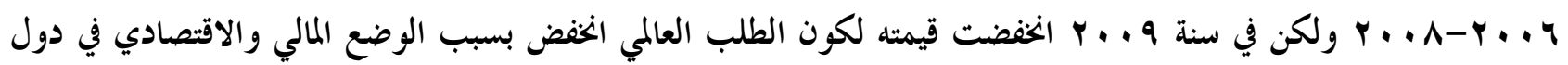

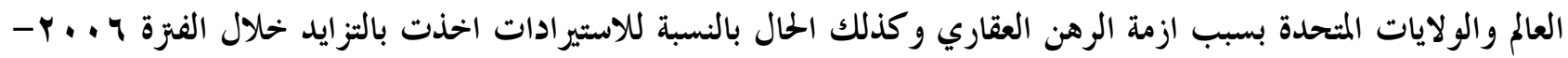

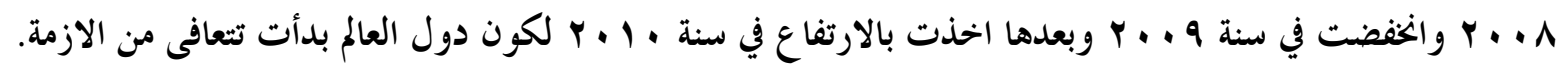

الاستثتاجات

ا ـ أزمة الرهن العقاري أدت المى انهيار كبير في الاقتصاد الأمريكي وانخفض مستوى استخدام الموارد الاقتصادية،وسحب مفاجئ

للودائع من المصارف نتيجة النقص الكبير في السيولة وعدم قدرة المصارف على الوفاء بالتزاماتها المالية. ץ. السبب الرئيسي لانفجار الفقاعة المالية استخدام سئ للمشتقات المالية والتوسع والافراط في منح القروض العقارية للأفراد والثر كات لقاء تسهيلات مصرفية وعدم تنويع في الضمانات والز كيز على الضمانات العقارية من قبل المصارف الامريكية. r. انخفاض واضح في المؤشرات المالية (مؤشر الربحية، مؤشر متانة رأس المال، مؤشر الودائع) خلال فنزة ازمة الرهن العقاري سنة 1 • . ץ في المؤسسات المصرفية الامريكية العملاقة (مؤسسة Citigroup، مؤسسة Bank of America، مؤسسة Lehman Brothers العمود الفقري للنظام المصرفي والمالي للاقتصاد الأمريكي. ع. انتشار الازمة الامريكية وتحولها المى ازمة مالية عالمية اصابت العديد من الدول النامية والمتقدمة ومنها الدول العربية، فأثبتت هذه الازمة حضورها في اقتصاديات الدول العربية بشكل مباشر وغير مباشر، فمنها ما تأثرت بشكل مباشرة وخاصة الدول النفطية والدول التي تتمتع بوجود أسواق الأوراق المالية المفتوحة على العالم ومنها ماتاثرت بشكل غير مباشر من خلال الاستير ادات والواردات.

ه. التذبذب الكبير في أسعار النفط وخاصة في الربع الرابع الأخير في سنة م ـ. . (ازمة الرهن العقاري) حيث انخفضت أسعار النفط المى النصف او اقل من النصف في سعره العالمي بسبب انخفاض كبير في الطلب على النفط وخاصة من قبل الولايات المتحدة ودول اوربا واليابان. 
4. تأثرت أسواق الأوراق المالية لدول الحليج التي تعد من الدول العربية التي لها ارتباط عالي مع الاقتصاد الأمريكي حيث

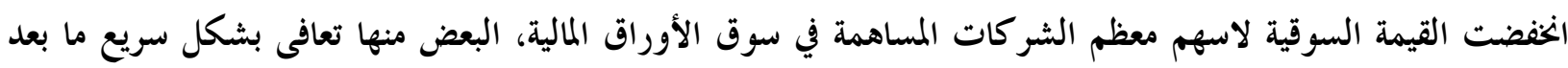
سنة الازمة والبعض الاخر اخذ فيه بالتباطئ في ارتفاع القيمة السوقية لاسهمه.

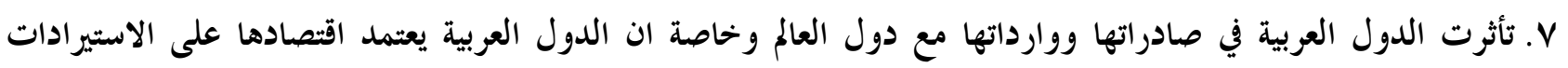
وجعل ارتفاع اسعار السلع المستوردة بسبب التضخم الذي لحق في الأسواق العالمية على الرغم من وجود حالات من

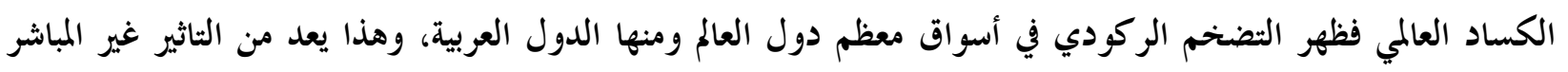
لازمة الرهن العقاري مع اقتصاديات الدول العربية. 1. معدلات نمو الناتج الخلي الإجمالي لدول العينة لم يظهر فية تاثير مباشر لأزمة الرهن العقاري الامريكية.

\section{المقزحات}

ا. الاعتماد على القطاع الصناعي بالنسبة للدول التي لديها القدرة على التصنيع وعلى القطاع الزراعي للدول الزراعية والتقليل من حجم الاستيرادات لتخفيف العبء على الميزانية وتقليل العجز بالميزان التجاري والاعتماد على الاستهلاك الخلي بدل من المستورد. r. الز كيز على كبر حجم الضمانات مقابل القروض الممنوحة للأفراد والشر كات. r. الابتعاد عن التعامل بأسلوب المرونة مع العملاء الذين يواجهون صعوبة في السداد للقروض وعمل جدول يتناسب ويتناسق بين العملاء والمصرف. ع ـ تبني مؤشرات الإنذار المبكر لمراقبة البيئة الداخلية والحارجية للتمكن من اكتشاف الازمة في بداية تكوينها. 


\section{المصادر}

\section{المصادر العربية}

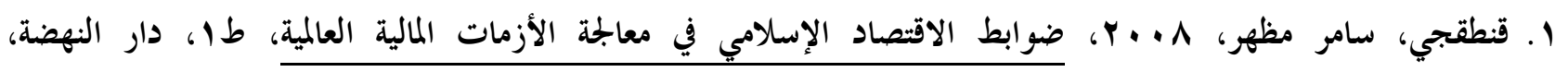
.WWw.kantakji.com

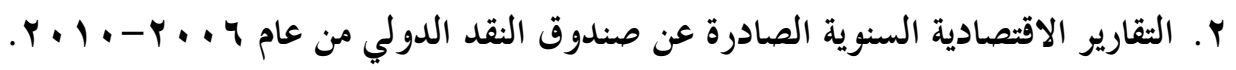

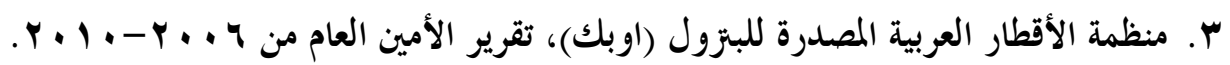

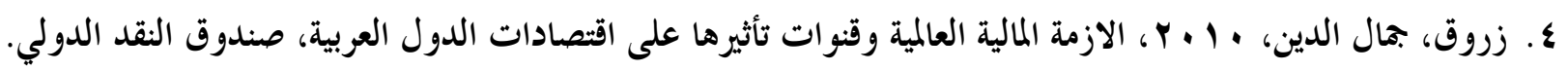
ه. إدارة البحوث والدراسات الاقتصادية، مجلس الغرف السعودية، م...r، الازمة المالية العالمية وتداعياتها على الاقتصاد

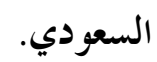

ج. كورتل، فريد، 9 . . ץ، الازمة المالية العالمية وأثرها على الاقتصاديات العربية ،كلية العلوم الاقتصادية وعلوم التيسير، جامعة سكيكدة، الجزائر.

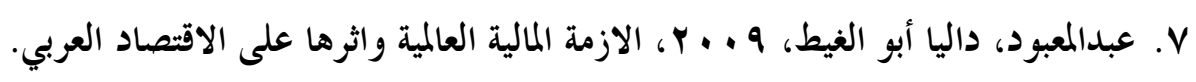

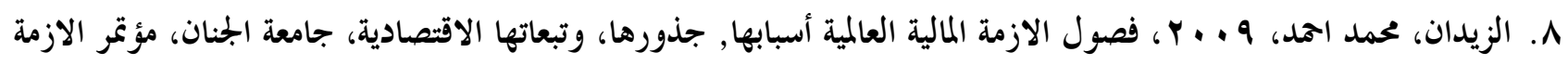
المالية وكيفية علاجها في منظور النظام الاقتصادي الغربي والإسلامي، طرابلس، لبنان.

9. Annual Report Bank of America, 2006, Building opportunities TM.

المصادر الاجنبية

10. Annual Report Bank of America, 2007, Bank of opportunities TM.

11. Annual Report Bank of America, 2008, Bank of America.

12. Annual Report Bank of America, 2009, Bank of America.

13. Annual Report Bank of America, 2010, Opportunities are everywhere.

14. Annual Report, 2007, Lehman Brothers.

15. Annual Report, 2010, Close Brothers Group plc.

16. Annual Report, 2014, Qatar Nation al Bank(QNB).

17. Citi Aunual Report, 2007.

18. Citi Aunual Report, 2008.

19. Citi Aunual Report, 2009.

20. Citi Aunual Report, 2010.

21. Citi group Aunual Report, 2006.

22. The global financial crisis, chapter7.

23. Mizen, Paul, 2008, the credit crunch of 2007-2008 A cliscussion of the background, Maket Reaction and policy Responess,fed eral Resene bank, Louis review. 
د. سر اء سالم داؤد الجرجوسي / م.م ليلى عبدالكريم محمد الهاشمي

أزمة الرهن العقاري وانعكاساتها في اقتصاديات...

24. Dick K, Aanto, 2009, the Global Financial Crisis: Analysis and palicy implecations, coordinator specialist in industry and tradem CRS, Report for congress.

25. Presbitero, Andrea, 2015, IMP Lending and Banking Crises Luca Papi, IMF Working paper.

26. Murphy, Austin, 2010,An Analysis of financial Crisis of 2008 causes and sdutions, Oakland University, SBA Rochester, MI.

27. Jickling, Mark, 2009, causes of financial Crisis cornell university, ILR School.

28. Kotte, Detlef, 2010, the financial and Economic Crisis of 2008-2009and developing united nations.

29. Zistler, Martin, 2010, Banking Crises Determinants and crises impact on fiscal cost and Economic output, Aato University School for Economics.

30. CFA Institute Pearson, 2008, Derivatives and Alternative Investments, Custon publishing, Boston.

31. Hershey, Friedman, linda, Friedman, 2009, the Global financial crisis of 2008, university of new york.

32. Sacred, Orlowski, 2008, Stages of the 2007/2008 Global Financial Crisis: Is there a wandering Assent-price Bubble? Heart University Halle Institute for Economic Research 10.

33. www.kantakji.con/fiqh/files/ Economic/11018.doc 